\title{
Paternally Derived Twinning: A Two Century Examination of Records of One Scottish Name
}

\author{
John B. St Clair' and Mikhail D. Golubovsky² \\ I Speculative Society of Edinburgh, United Kingdom \\ ${ }^{2}$ Department of Evolutionary Theory, Institute of the History of Science and Technology, Russian Academy of Sciences, Russia
}

\begin{abstract}
aternal influence on twinning was investigated through a study of all the state and church records of Scotland for the period 1800-2000 (nine generations) in relation to one Scottish patronymic - in total 50,000 births. All recorded twins born with the chosen patronymic were identified and their whole paternal ascent and descent on the male line were charted for twins. There were established three pedigrees A, B and C manifesting clear paternal twinning hereditary transmission. Detailed familial reproduction patterns were traced for pedigree $A$, including phenotypic identification of twin zygosity in relation to seven same sexed pairs of twins in the pedigree and one same sexed pair out of dizygotic triplets. It is the most comprehensive description to date of such a kind of twin familial trait. The data presented show (i) the unique feature of clear direct paternal influence on twinning in three families; (ii) paternal factor(s) determination in both DZ and MZ twinning; and (iii) a definite association of twinning tendency with a partial male infertility, which corresponds to the prediction of the Infertility/Twinning Paternally Dependent syndrome hypothesis. The hypothesis of a founder effect explaining the similarity of A, B, C families and the possible localisation of the paternally dependent twinning factor on the Y-chromosome are currently under molecular investigation.
\end{abstract}

The question of the existence of "paternally derived twinning" is an old scientific puzzle. The question concerns a direct paternal genetic influence on the twinning incidence in the female sexual partner and is different to the transmission of twinning factors(s) from fathers to daughters, like the transmission through bulls of milk productivity genes to cows. In the related field of animal genetics Lush (1925) studied inheritance of twinning in a herd of Holstein cattle and gave the example of a sire named "Quad" who was bred to six Holstein cows nine times with six pairs of twins resulting (DZ and MZ). The same cows were bred 14 times to other sires with no twins. Davenport (1920) and Peiper (1923) had first suggested twinning inheritance through the male, followed by an extensive literature documenting such inheritance in humans and animals (Kanaev, 1959).

Paternally derived twinning in humans is not yet scientifically accepted. As regards DZ twinning, with important exceptions (Michels \& Riccardi, 1978; Parisi et al., 1983) the researchers have been sceptical of a paternal influence (Bulmer, 1970; Khoury \& Erickson, 1983; Lil'in \& Gindilis, 1976). As regards MZ twinning, the opinions have again been divided. Lil'in and Gindilis (1976) on the basis of statistical evidence concluded that in $\mathrm{MZ}$ twinning both the mother's and father's genotypes performed as multiple birth factors. Harvey et al. (1977) using pedigree evidence found in three out of six cases of parent to offspring $M Z$ twinning that the inheritance appeared to be through the paternal line. However, also using statistical evidence, Parisi et al. (1983) found no evidence of a paternal influence on $M Z$ twinning, although they thought $M Z$ twinning related to $\mathrm{DZ}$ twinning where they had found a paternal role. Lichtenstein et al. (1998) concluded from a statistical analysis of the Swedish Twin Registry that there was no evidence for a paternal effect on MZ twinning.

Paternally derived twinning is not only disputed, it has surprisingly been neglected. Why should this be? The reason appears to have been the absence of an up-to-date theory to explain the phenomenon. Davenport (1920) had suggested the absence of lethals in sperm as a cause and Southwick (1939) the absence of other fertilization limiting factors. But these theories considered the pre-eminent contribution to the twinning process to be the maternal multiple ovulation, which could not of course explain phenomena such as non-canonical twins. The first hypothesis explaining a direct male contribution to twinning was based on reproductive genetics data (Golubovsky \& Golubovskaya, 1984). Alongside the theory was a description of a pedigree of a family in which infertility was associated with multiple births (Golubovsky, 1984). This association has since been further developed, taking into account a series of new discoveries in reproductive genetics including hydatidiform moles and the molecular study of unusual human chimeras. The existence of a distinct biological entity has been put forward labeled the "Infertility/ Twinning Paternally Dependent" (“ITPD”) syndrome (Golubovsky, 1998, 2002).

The ITPD syndrome hypothesis was at the level of gamete genetics, based on findings made about the interaction of three basic reproductive processes: meiosis and gametogenesis, fertilization and early embryogenesis. The

Address for Correspondence: John B St Clair, 35 Lismore Crescent, Edinburgh EH8 7DL United Kingdom.Email: john.stclair@ scotland.gov.uk 
theory postulated three possible scenarios which could lead to the appearance of two male pronuclei in the egg, with subsequent double fertilization of two female meiotic products. There existed definite paternal genes which, expressed at the level of the male gametes, could lead to this happening through (1) dispermy; (2) heterochronous mitotic division; or (3) a male meiotic mutation like diplospermy. The hypothesis did not claim to encompass all genetic mechanisms of paternally derived twinning. What it did aim to do was to try to give a concept, which was in accordance with and could explain all significant known phenomena in relation to paternally derived twinning.

The concept made certain predictions. These were: (a) that paternally derived twinning was linked to male infertility, and indeed could be looked at as a fortunate side effect of that infertility; (b) that there would occur in paternally derived twinning families unusual twins that may properly be described as "sesquizygotic" or "SZ" twins — intermediate between $\mathrm{DZ}$ and $\mathrm{MZ}$ - who would usually pass as dissimilar MZ twins; and (c) that there would occur in such families chimeras among both twins and their sibs.

This paper has the following aims: (i) to present a description of long pedigrees with families with clear direct paternal influence on twinning; (ii) to describe the reproduction pattern of such families including type of zygosity; and (iii) to elucidate to what extent the paternal hereditary influence on twinning discovered corresponds to the predictions of the Infertilitity/Twinning Paternally Dependent syndrome hypothesis.

\section{Materials and Methods \\ Finding Pedigrees}

Finding pedigrees with clear paternal twinning of the necessary profile to verify the ITPD syndrome hypothesis required more than interesting local fragments with some indicators of paternal twinning. Long pedigrees were necessary with an unmistakable inheritance pattern over many generations. The pedigrees also had to have a living base substantial enough to exhibit the ITPD syndrome pattern of infertility and substantial enough to allow molecular investigation.

With the above desiderata in mind, an examination was made of all the state and church vital records of Scotland (which go back to 1560 , although incomplete) for the period 1800 to 2000 in relation to the patronymic St. Clair in its various spellings - a total of 50,000 births. In making the examination of the records, a policy was adopted of strict verification of all cases of twinning. Reliance almost exclusively on state and church written records was designed to avoid the problems of oral evidence, especially in questions of twinning and relationships. Only in the case of two still births (which at the time were not subject to registration) was oral evidence accepted. All recorded twins born with the chosen patronymic were identified and their whole paternal ascent and descent on the male line were charted for twins. Charting was not pursued where the ascent could not be traced back to 1800 or an illegitimacy was encountered which changed the patronymic. It was known at the start of the study that the name was spread widely over Scotland, but that in the majority of cases kinships were unlikely to be related as the name usually had not been a patronymic but had been a landlord's name which attached to those working his land. Only in certain lowland areas where a proper patronymic had been used for many centuries was there a distinct possibility that kinships might be related.

The main purpose of the method of investigation was not to gather statistics, although some useful demographic data on twinning might be yielded as a by-product. The sole purpose was to flush out pedigrees with paternally derived twinning. Only by dragging the whole pool of state and church records in relation to one patronymic, was it feasible to attempt to chart for twins the complete male ascent and descent of each pair of twins and catch collateral lines through siblings and more distant male relatives. The dragnet approach of course does not work at all for maternal twinning, as there is no matronymic.

The patronymic St. Clair was chosen because it was the patronymic of the proband twins (Figure.1, Diagram A, VII-14,15). Before the examination of the records was begun, two other sets of twins in the probands' immediate family on the male line had been identified - suggesting the existence of a possible paternally derived familial twinning inheritance pattern. A second reason for the choice of the patronymic was because the proband twins had been a case of doubtful zygosity and theoretically might be candidate SZ twins (St Clair et al., 1998). From the earliest age they and all their family had presumed they were DZ. They were discordant for handedness and laterality of occipital hair whorl, and one twin had heterochromia iridum. In most other respects they were phenotypically similar (see photograph in St Clair et al., 1998). As argued by Machin (1996), such discordances or dissimilarities may be attributable to postzygotic events exhibiting themselves as different patterns of expression of imprinted genes and slightly distinct developmental profiles. The probands were ascribed MZ zygosity following RFLP DNA molecular analysis which showed the identity of four DNA restriction markers, and on the basis of this zygosity ascription, renal transplantation immunotherapy treatment was withdrawn (St Clair et al., 1998).

There was one final reason for using a dragnet approach of using only one patronymic. Even if genealogical evidence could not link up pedigrees of the same patronymic which had promising but inconclusive apparent paternal twinning, molecular tests for a common male ancestor could now do that - yoking them together to reveal a higher overarching genealogical pattern.

\section{Profiling of Reproduction Patterns}

In profiling for reproductive abnormalities, information was obtained covering all members of the family over the last three generations, detailing as far as possible (a) the intervals between marriage or start of cohabitation and births of children; (b) miscarriages and spontaneous abortions; (c) still-births; and (d) any other known reproductive problems or congenital abnormalities. Any other twinning in the family was also noted.

From the start of the profiling exercise the difficulty of evaluating possible indicators of infertility was recognised. 
Unless persons present themselves at an infertility clinic, they are often unwilling to admit infertility. The approach of the Internat standard is acknowledged as a useful measurement of the likelihood of sub-fertility. That standard stipulates that, if there is not a child within two years of full sexual relations (i.e., marriage or cohabitation), this gives an advance indication of sub-fertility. In this paper a more conservative approach was adopted using a three-year period as an indicator of sub-fertility.

The Internat standard is subject to the absence of contraceptives. Whether contraception was used has to be gauged from all the circumstances of each case, including personal testimony, religious beliefs and social attitudes, and the availability of contraceptives. Finally fertility depends on male and female, and with any individual couple it will be difficult to determine where the infertility lies. The approach adopted therefore was to inquire whether there were patterns of infertility, and to seek to gauge from those patterns whether at any one generational level of the pedigree the source of the infertility was likely to be male or female or from both.

\section{Results}

\section{Paternally Derived Twinning Pedigrees}

The search of the Scottish church and state records (1800-2000) found 532 multiple births. After deducting 61 cases of illegitimacies or otherwise untraceable lines, there were 471 multiple births ("the study group") comprising 465 sets of twins and 6 sets of triplets. Because there were well over 1000 marriages between 1790 and 1815 of persons of the same patronymic, it is clear that a majority of the families of the patronymic descended from these marriages had no incidence of twinning over the 200 year period - underlining the importance of familial twinning.

\section{Twinning Frequencies}

The 471 study group consisted of 336 pedigrees descended on the male line from 336 ancestors born before 1800. The twinning frequencies on the male line in the 336 pedigrees can be seen in Table 1 .

The clear implication of these figures, coupled with the other demographic evidence, was that paternally derived twinning was likely to be present in some of the paternal twinning families but that in the families represented by Diagrams $\mathrm{A}, \mathrm{B}$ and $\mathrm{C}$ there was for the first time a unique cluster of families where paternally derived twinning was unmistakable.

Recognising the importance of the discovery of this cluster of paternal twinning families, a program of examination of them was undertaken, starting with Family A, profiling for zygosity, infertility and reproductive abnormalities. This has already yielded data on reproductive abnormalities more comprehensive than in all previous studies of this kind.

\section{DZ and MZ Paternally Derived Twinning in Family A}

The presence of so many same sexed sets of twins in Family $\mathrm{A}$ indicated that the pedigree must include some $\mathrm{MZ}$ twins as well as DZ twins. However the presence in the pedigree of one set of $M Z$ twins or even two such sets could always be explained as the crossing of a maternal line carrying such

\section{Table 1}

Twinning Frequencies on the Male Line

\begin{tabular}{lcl}
\hline No. of Pedigrees & No. of sets & \\
\hline 248 & 1 & \\
$64^{*}$ & 2 & \\
$19^{*}$ & 3 & \\
2 & 4 & Figure 2 Diagram C \\
1 & 8 & Figure 2 Diagram $B$ \\
1 & 11 & Figure 1 Diagram $A^{* *}$ \\
1 & 11 & \\
336 & & \\
Total & & \\
\hline Note: * In the 64 pedigrees with two sets, 20 mothers had two sets. In the 19 pedi- \\
grees with three sets, 5 mothers had two sets and one mother had three sets. \\
"Twinning" includes triplets. \\
** In addition to 11 sets of twins on the paternal line, Diagram A shows on the \\
female line in generations VIII and IX one set of live twins and two sets of mis- \\
carried twins.
\end{tabular}

a twinning tendency. Accordingly an examination was made by G Machin of all the same-sexed twins in Family A to try to determine zygosity. (Only in relation to twins AVI-4,5, which included a stillbirth, was no attempt made to ascertain zygosity because no data survived on which such a determination could be made). The results described below of the examination showed such a prevalence of MZ twinning among like-sexed twins as to rule out stray maternal twinning line(s) causing all the $\mathrm{MZ}$ twinning.

On the basis of phenotype similarity from photographic evidence 2 sets of twins AVI-12,13, and AVIII-9,10 were attributed MZ zygosity. On the basis of molecular analysis twins AVII-14,15 were attributed MZ zygosity. On the basis of case notes of their birth and statistical likelihoods (Machin \& Bamforth, 1996) the like sexed twins AVII-4,5 out of dizygotic triplets AVII-3,4,5 were attributed probable MZ zygosity. Similarly on the basis of case notes of births and medical diagnosis of MZ zygosity at birth, twins AVIII-9,10 were attributed probable MZ status. Only twins VIII-11,12 were attributed DZ zygosity.

Interestingly twins AVIII-9,10, who were classed as dissimilar MZ by Professor Machin, had thought all their lives that they were DZ and had been thought such by their parents. According to a recent study parental ascription of zygosity is $93 \%$ accurate in comparison to DNA testing (Rietwald et al., 2000). This case of mistaken zygosity was in addition to that of proband twins AVII-14,15 (St. Clair et al., 1998).

\section{Infertility and Other Abnormalities in Family A}

The details of the profiling of Family $\mathrm{A}$ as at 1st January 2001 are given in Diagrams D, E, F and G (Figures 3, 4 and 5), which cover respectively four branches D, E, F, and $G$, into which the family has been divided. Diagram D shows the descent of AVII-1,2. Diagram E shows the descent of AVI-2,3. Diagram F shows the descent of AV3,4. Diagram G shows the descent of AV-5,6.

\section{Analysis of Data}

Diagram D shows indicators of infertility in this branch of the family. However a complicating factor in this branch is 
a possible maternal twinning line consisting of three sets of twins, namely a) the DZ same-sexed male twin sibs of DVII1 (See Diagram H); b) the DZ twins DVIII-5, 6; and c) the DZ same-sexed male twins DIX-9,10. That possible maternal line also exhibits a pattern of inherited abnormalities.

Diagrams E shows indicators of infertility. The reproductive pattern set out is highly unusual. Over a 15-year period EVI-1,2 produced nine children including a set of probably dizygotic triplets and a set of dizygotic twins. There is a particularly pronounced pattern of sub-fertility in the second generation. The inheritance is predominantly through the female line but there are also indicators of infertility in the line through EVII-13, who was the only surviving male at that level.

Diagram $\mathrm{F}$ comprises the whole known descent of AV3,4. There were eight surviving children of AV-3,4 with six descending lines, that is, through (i) FVI-1; (ii) FVI-4; (iii) FVI-8 (iv) FVI-10; (v) FVI-12; and (vi) FVI-14. There are indicators of sub-fertility in all (apart from that of FVI-8) of these descending lines vouched by personal testimony. Apart from FVI-1, all the descending lines are through the male line (which distinguishes this descent from that of EVI-1,2, which is predominantly through female descending lines).

Diagram G shows evidence of severe congenital abnormalities in the case of GVI-3,10, and familial heart problems. There are possible indicators of sub-fertility in that MZ twins FVI-5,6, had only one child each, and the son of twin FVI-5 (FVII-5) had no children in 20 years of marriage, and the daughter of twin FVI-6 (FVII-6) had only one child.

\section{Conclusion on Sub-fertility Question}

There are clear indicators of a pattern of sub-fertility in all branches of Family A, except branch G, where there is less information available. It is expressed in both males and females. It is expressed most strongly in branch $E$ and branch $\mathrm{F}$, where there are clustering of twins. In branch E, where the line of descent is largely female, the pattern indicative of sub-fertility is expressed mainly in the females, whereas in branch F, where the line of descent is largely male, it is expressed in the males.

\section{$\overline{\text { Discussion }}$}

The first stage of proof of the ITPD syndrome involves establishing the existence of paternally derived twinning. Although the concept of paternally derived twinning goes against the current orthodoxy, it is suggested that the extensive documentation of its existence in both humans and animals makes it surprising that it is still denied. Not only $\mathrm{DZ}$ twins have been recognised as paternally derived (Parisi et al., 1983) but also MZ (Harvey \& Huntley, 1977) and also the simultaneous occurrence of both $\mathrm{DZ}$ and $\mathrm{MZ}$ twins (Michels \& Riccardi, 1978). Michels and Riccardi attributed the neglect and denial of the phenomenon to entrenched opinion and the weakness of statistical or population based approaches. Additional genealogical evidence of a paternal contribution to twinning was reported in the case of Utah Mormon genealogies by Carmelli et al. (1981).

\section{Limitations and Implications of Evidence Adduced}

The best evidence of a suggested genetic twinning mechanism would be a full molecular and biological elucidation. Until such an elucidation is achieved, it is suggested that the best evidence of a paternal inheritance factor would be the production of well documented pedigrees with a high incidence of twinning over many generations predominantly on the paternal line, configured in patterns suggestive of paternal inheritance. The data would have to be robust enough to rule out alternative explanations of the incidence and pattern of the twinning.

\section{Documentation of Pedigrees and Other Data}

The primary data compiled from the study consisted of fragments of pedigrees, which had been selected with a built in bias only to reveal paternal side twinning. The quality of the data was vouched in two ways. Unlike most statistics based enquiries, reliance was placed solely on fully constructed pedigrees showing all twinning on the chosen line over a 200-year period. Secondly live twins were documented exclusively by state and church written records. In pilot studies oral evidence was found to be unreliable. Mormon records were also found unreliable and incomplete.

The hypothesis of a direct paternal effect on twinning did not require examination of the maternal line at the primary data gathering stage. However once pedigrees had been constructed showing an exceptionally high incidence of paternal twinning, maternal side twinning was investigated and documented as far as was reasonably possible. Because there is no matronymic and maternal twinning inheritance is postulated as transmitted through both parents, maternal side twinning cannot normally be as fully charted as paternal twinning, except in small isolated communities - which would not be big enough for this type of study. In the case of Family A, of which the data is presented, a full pedigree over the last three generations was also established, giving a comprehensive reproductive profile. Medical details were extracted from death certificates or medical records, or based on oral evidence corroborated where possible by medical documentation. Finally, in Family A zygosity was also made subject to almost complete ascertainment.

\section{Incidence of Twinning in Families A, B and C/ Statistical and Environmental Evidence}

The two century study of actual pedigrees covered 50,000 births and over 1000 pedigrees. The number of twins on the paternal line in families A, B and C so far outstripped the number in the other 333 pedigrees of the study group as statistically to set them apart. The number of twins in families A, B and C were also too numerous to be the result of randomness. Robinson Crusoe could wonder about one footprint in the sand. Could the wind have made it? But not when a pattern of footprints is found. Randomness could not be the explanation, although an element of randomness could not be ruled out.

Maternal age was also looked at but could not statistically explain the high incidence of twinning. Even in the high risk age of 35/40 years (when the twinning rate is 14 in 1000 or over 4 times that of a women under 20 where it is 3 


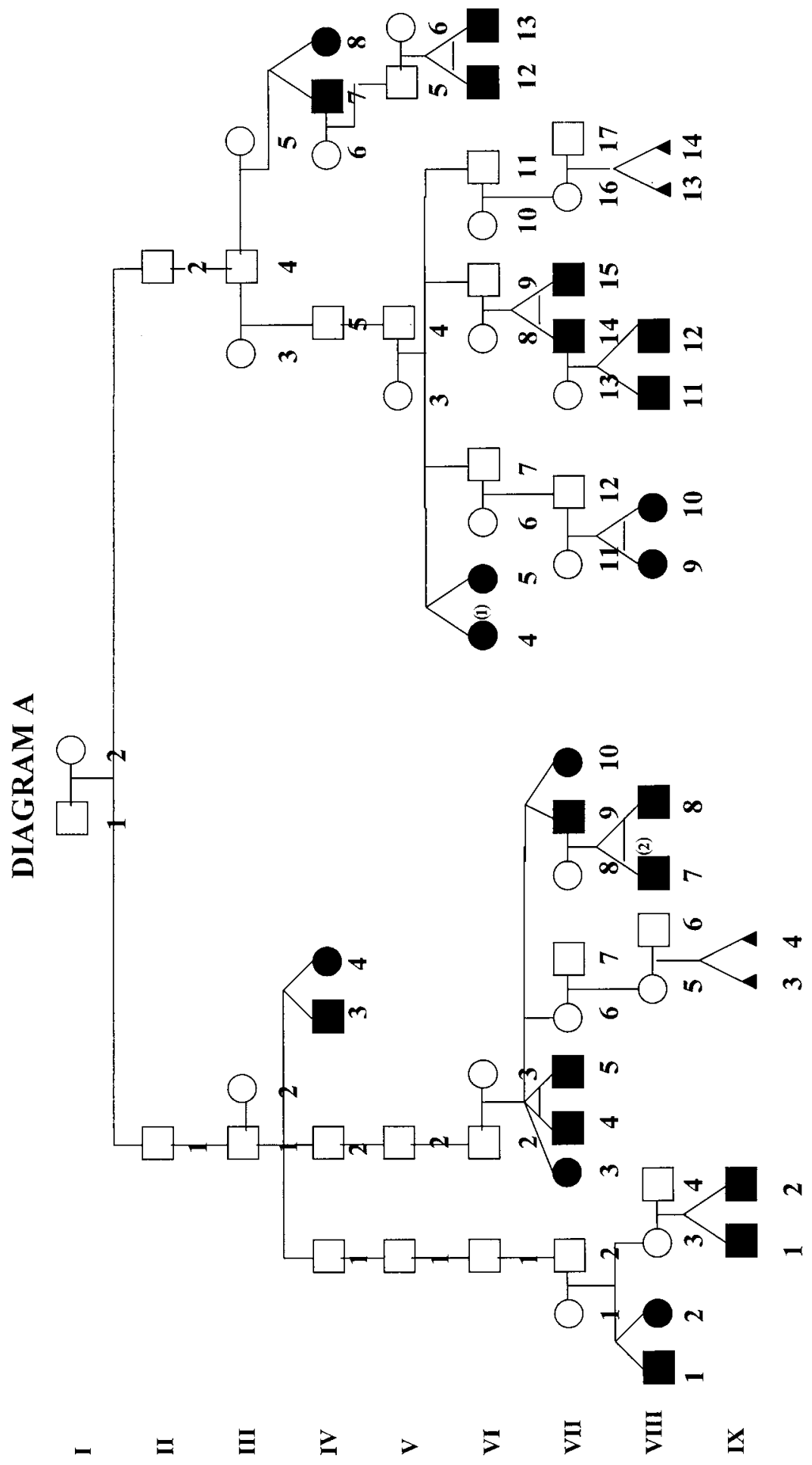

Figure 1

Diagram A shows a fragment of a pedigree with predominant paternal familial twinning and occurrence of both DZ and MZ twins. It was compiled from a study of all the state and church records of Scotland for the years 1800 to 2000 in relation to the St Clair patronymic in its various spellings. The zygosity status of the proband twin pair AVII-14,15 was described in the genetics/molecular study (St Clair et al., 1998). The zygosity of other cases of same-sexed twins is indicated in accordance with their phenotypic examination. Triangles correspond to twin miscarriages. Still births are indicated by footnotes. The Diagram shows only twins on the paternal line, except for the last three generations where all twinning is included. In total on the paternal line there are 11 sets of twins (including a set of triplets). In the last three generations on the maternal line there is one set of twins and two miscarried sets of twins. Numbers in parentheses refer to footnotes that appear at the end of this article. 

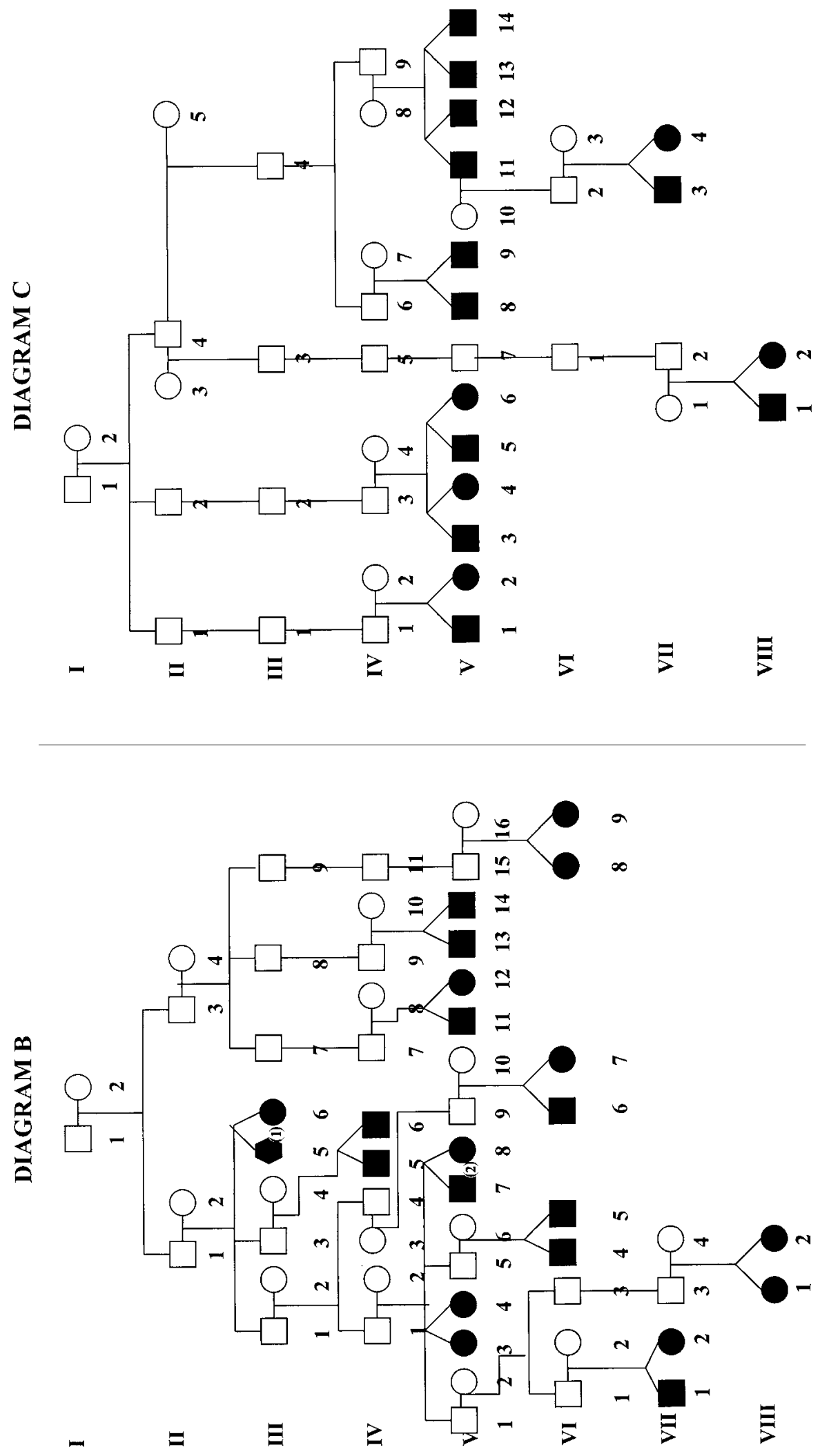

Figure 2

Diagrams B and C show pedigree fragments of two other families of the St. Clair patronymic with clear paternal hereditary influence on twinning tendency. Zygosity status of like sexed twins has not been attributed and the Diagrams show only twins on the paternal line. Numbers in parentheses refer to footnotes that appear at the end of this article. 

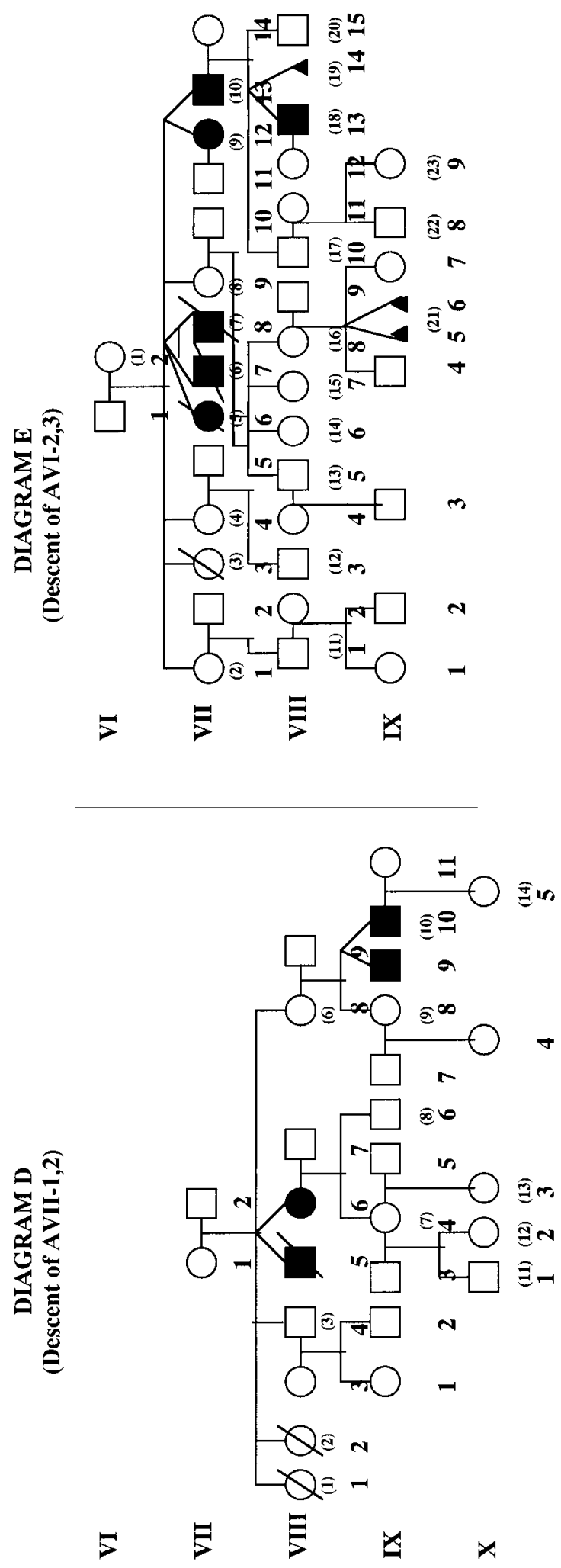

\section{Figure 3}

Diagrams $D$ and $E$ and corresponding footnotes show the complete reproductive pattern of two branches of the $A$ family. Diagram " $D$ " shows all descents of the AVII-1,2 marriage pair and Diagram "E" shows all descents of the AVI 2,3 pair.

Designations: triangles indicate early abortions, miscarriages and still births; oblique lines indicate death before 1 year; and the number in the bracket corresponds to the number in relevant footnote where is indicated the time of birth of each individual after the marriage (letter " $\mathrm{m}$ " and then " + " followed by the number of years/months) together with a brief indication of any relevant reproductive peculiarities. Numbers in parentheses refer to footnotes that appear at the end of this article. 


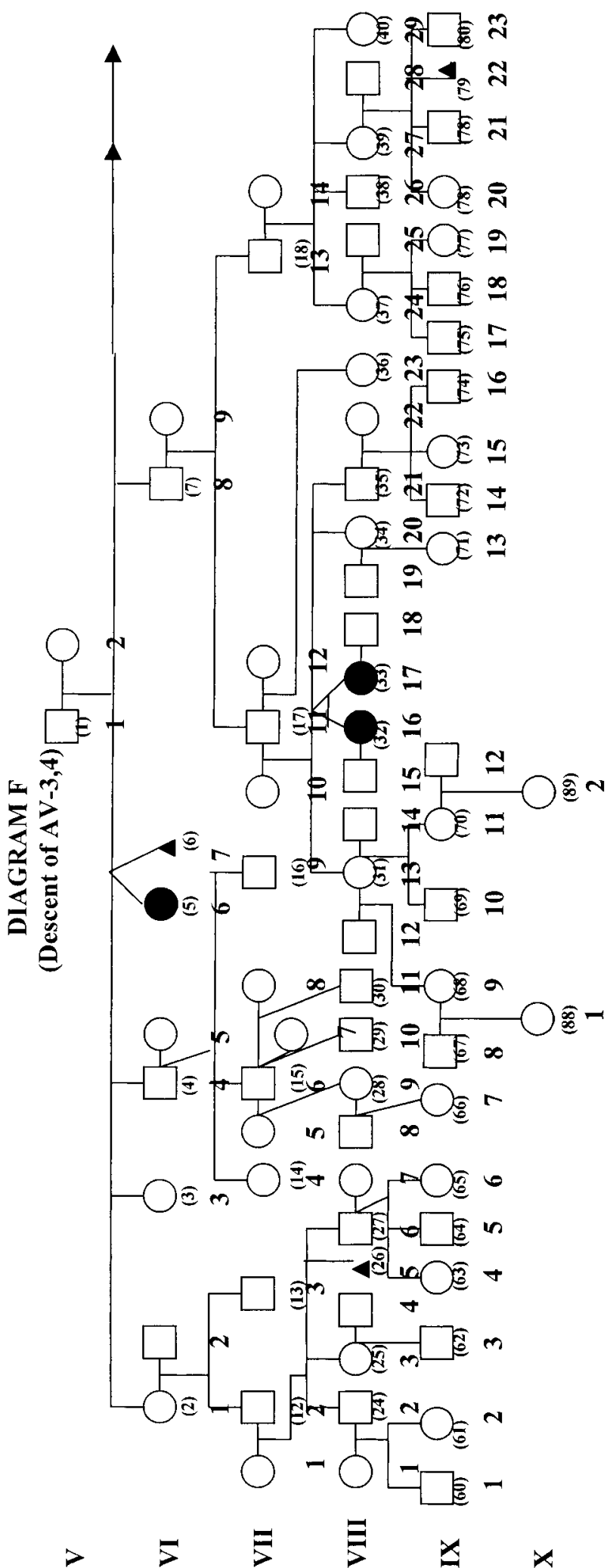

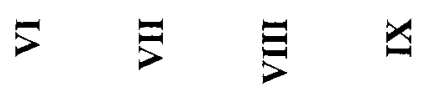

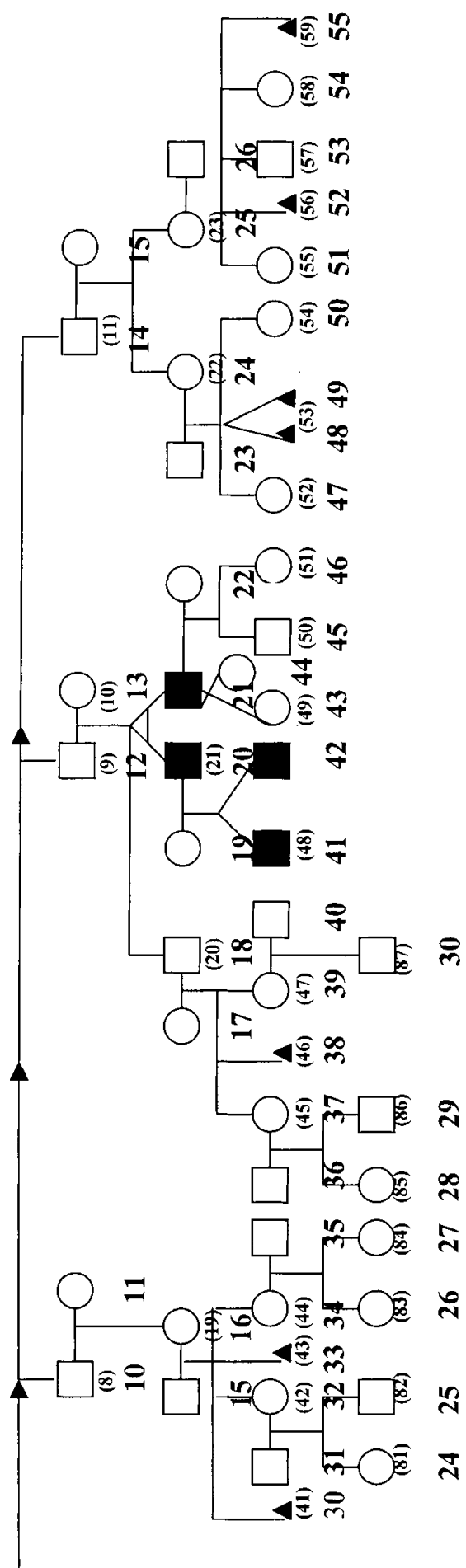

Figure 4

Diagram $\mathrm{F}$ and footnotes show the complete reproductive pattern of a third branch of the A family, namely all the descents of the AV-3,4 marriage pair. This pair had seven singleton births and one twin birth during a 21 year child delivery period. Other designations are the same as in the Figure 3. Numbers in parentheses refer to footnotes that appear at the end of this article. 

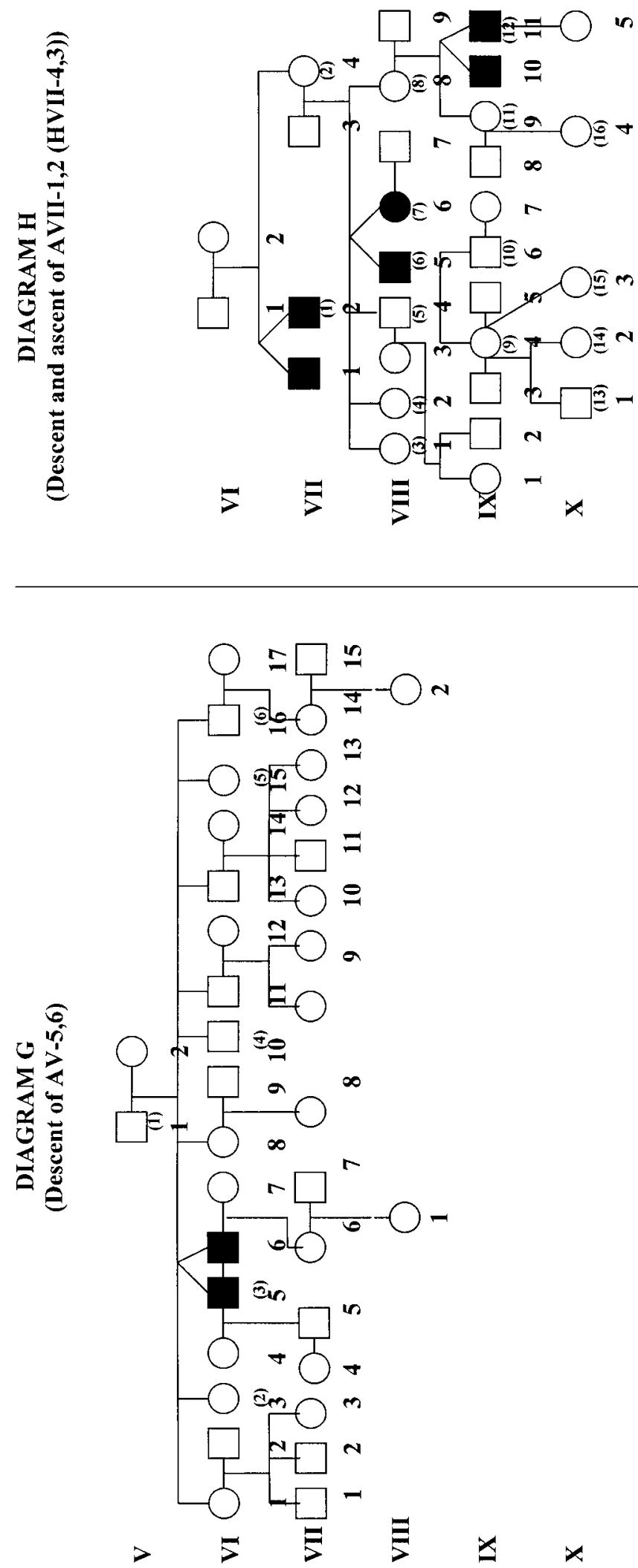

\section{Figure 5}

Diagrams $\mathrm{G}$ and relevant footnotes show the complete reproductive pattern of a fourth branch of the A family, namely all the descents of the AV-5,6 marriage pair. Diagram H incorporates most of Diagram D showing all the descents from the AVII 1,2 marriage pair, but also shows a fragment of the ascent of AVII-1. Zygosity status is attributed in accordance with phenotype examination. Other designations are the same as in the Figure 3. Numbers in parentheses refer to footnotes that appear at the end of this article. 


\begin{tabular}{|c|c|c|}
\hline \multicolumn{2}{|c|}{ Family Twins } & Age of Mother at \\
\hline $\mathbf{A}$ & $\begin{array}{l}\text { AIV-3,4 } \\
\text { AIV-7,8 } \\
\text { AVI-4,5 } \\
\text { AVI-12,13 } \\
\text { AVII-3,4,5 } \\
\text { AVII-9,10 } \\
\text { AVII-14,15 } \\
\text { AVIII-1,2 } \\
\text { AVIII-7,8 } \\
\text { AVIII-9,10 } \\
\text { AVIII-11,12 } \\
\text { AIX-1,2 }\end{array}$ & $\begin{array}{l}38 \\
39 \\
30 \\
34 \\
32 \\
\text { 38 } \\
42 \\
27 \\
27 \\
23 \\
34 \\
\text { 30 }\end{array}$ \\
\hline B & $\begin{array}{l}\text { BIII-5,6 } \\
\text { BIV-5,6 } \\
\text { BV-3,4 } \\
\text { BV-7,8 } \\
\text { BV-11,12 } \\
\text { BV-13,14 } \\
\text { BVI-4,5 } \\
\text { BVI-6,7 } \\
\text { BVI-8,9 } \\
\text { BVII-1,2 } \\
\text { BVIII-1,2 }\end{array}$ & $\begin{array}{l}41 \\
38 \\
38 \\
45 \\
20 \\
33 \\
35 \\
35 \\
19 \\
\text { 30 } \\
27\end{array}$ \\
\hline $\mathbf{C}$ & $\begin{array}{l}\text { CV-1,2 } \\
\text { CV }-3,4 \\
\text { CV-5,6 } \\
\text { CV-8,9 } \\
\text { CV-11,12 } \\
\text { CV-13,14 } \\
\text { CVII-3,4 } \\
\text { CVIII-1,2 }\end{array}$ & $\begin{array}{l}30 \\
29 \\
42 \\
29 \\
33 \\
44 \\
31 \\
32\end{array}$ \\
\hline
\end{tabular}

Figure 6

Sets out the ages of the mothers of twins in Diagrams A, B and C, as at the date of the birth of the twins and as referenced in those diagrams.

in 1000), the rate is still 1 in 71 - or not much above the average twinning rate of 1 in 80/90. In any event as detailed in Figure 6, only in 7 out of the 30 twin births (less than a quarter) was the mother's age in the 35/40 bracket.

There was also no known environmental connection which could explain a higher than normal twinning rate. The twins were born mostly in geographically separated locations in Scotland away from heavy industry or industrial pollution. There seemed to be nothing in fact to distinguish families $\mathrm{A}, \mathrm{B}$ and $\mathrm{C}$ from families where twins were not prevalent.

\section{Maternal Involvement}

Statistically any pedigrees as large as those of families A, B and $\mathrm{C}$ are likely to intersect a maternal line. But could sup- posed maternal lines explain all the paternal line twins in these families? There were no closely related families with multiple marriages between families by different members. Statistically one, two, three and perhaps even four sets in a pedigree could be explained in this way. In Family A, where the whole inheritance pattern of the last three generations is available, the evidence ruled out such an explanation. In that family, as expected, we did find one probable maternal line, namely the descending line of the pedigree having twins AVIII-1,2 and AIX-1,2. This likelihood of maternal involvement was strengthened by the existence of a further set of twins on that apparent maternal line at level VII, as shown in Diagram H (Figure 5).

In the other three descending lines, namely those from AVI-2,3, AV-3,4, and AIII-4,5, there was no known maternal 
twinning line from which the twinning could be derived. The two miscarried sets of twins AIX-3,4, and AVIII-13,14 were indeed descended from the founders of the descending lines through female members of the descending lines, but they were not indicators of any maternal line prior to the founders. The only other twinning known in the background to the two main descending lines from AVI-2,3, and AV-3,4 concerned male members of the families being fathers of twins, namely a brother of AVI-3 and a maternal male cousin of AVI-8. The mothers of the twins concerned were not related to pedigree members. In other words the credentials of the paternal lines through AVI-2 and AVI-9 could only be called into question if the sceptic were to accept paternally derived twinning elsewhere in the pedigree. In any event the argument would still not account for the other twins descended from AIII-1 or AIII-4, nor twins AVIII-7,8, and twins AVIII-11,12.

\section{Further Evidence of Predominant Paternal Involvement in Family A}

If we look at Family A, we see a number of indicators of a predominant paternal inheritance pattern, (which further argue against randomness or statistical aberration) such as (a) two instances of a male twin having twins (twin AVII-9 having twins AVIII-7,8, and twin AVII-14 having twins AVIII-11,12); (b) a male critical intermediary between two sets of twins (AV-5) and five male critical intermediaries between the two main branches of the pedigree (AI-1, AII1, AIII-1, AII-2 and AIII-4); and (c) two clusterings with predominantly paternal twinning patterns ( the descending line from AVI-2, and that from AV-4). Other suggestive indicators are: paternal male first cousins having twins (AVII-12 and AVII-14); twinning spread over five generations with only one gap; and the paternal tendency going down both wives of AIII-4. The only exception is the one instance already acknowledged of likely maternally derived twinning, namely the descending line of the pedigree (through AVII-1,2) comprising twins AVIII-1,2, and AIX-1, 2. However one line of outside interference is to be expected in a pedigree as large as Family A, and it would be surprising, if no such interference had been found. The predominant pattern is paternal inheritance, and it is deeply and unmistakably woven into the fabric of pedigree A.

\section{Sex-limited Versus Y-Chromosome Inheritance}

Looking now at what actual genetic factor/s are likely to be causing the paternally derived twinning in Family A, two main genetic scenarios are suggested: a) the factor/s is transmitted through both male and females, but its statement is sex-limited predominantly in males; b) the predominant paternal transmission is the result of the localisation of the relevant factor on the Y-chromosome which is transmitted on the male line.

The first scenario involves the transmission through both sexes of a certain dominant factor/s with predominant activity in the male gametes during the fertilization process. Thus the gene which, for instance, might promote an increased incidence of dispermy, might be expressed predominantly in male gametes but be transmitted through both males and females. The process of fertilization has now been analysed as the molecular dialogue between male specific proteins on the sperm membrane surface and female specific receptors on the egg membranes. It encompasses at least five steps involving cell adhesion molecular egg-sperm recognition processes (Wasserman et al., 2001). It is easy to imagine that mutations of specific sperm eggbinding proteins may have strong paternal dependent influence having no statement in females (and vice versa). A sex-limited statement of certain mutations in the fertilization process would not of course preclude their unpredictable action in other tissues and organs, such as with Kartagener syndrome. The general concept suggested by the first scenario is clear and at this stage other or more detailed speculations are premature.

The second scenario suggests factor(s) that are transmitted on the Y-chromosome. In this case it would be the predominant vertical transmission of paternal twinning influence from father to sons - the intuitively obvious explanation. The Y-chromosome was long thought to be genetically inert apart from localization of the SRY gene controlling sex-determination. In the last two decades, however, there was found clustering in the long arm of the Y-chromosome factors which in the case of deletion or damage lead to impairment of spermiogenesis and infertility. At least 12 distinct factors relating to sperm abnormalities are localized in the Y-chromosome (McElreavey \& Fellous, 1999). These facts open other possible variants on this scenario - Y localized mutations which far from diminishing sperm activity actually activate it with dispermy as an indirect consequence. We can not now exclude that some mutations of the Ychromosome factors may induce block of meiosis and lead to the diplospermy.

The second scenario meets a difficulty evident on observation of A pedigree. First, there are three cases of the twinning tendency transmission through females: in AIX1,2 , and the two sets of miscarried twins, AIX-3,4, and AVIII-13,14. In the case of twins AIX-1,2, it is accepted that maternal twinning is likely to be involved, and in the other cases, where there is no evidence of maternal twinning, it is not hard however to invent formal reasons why in some case the Y-chromosome inheritance may be disrupted. There could be X-Y recombination, or if postulated that the $\mathrm{Y}$ factor acts as transcriptional regulator, there may be autosomal constitutional mutation of the down-regulated gene et cetera: as the model may be the explanation of the appearance of XX males without the SRY master gene (McElreavey et al., 1993).

\section{Conclusions}

The first stage of the proof of the validity of the ITPD syndrome hypothesis has been accomplished by the presentation of families with clear paternally derived twinning. The reproductive profiling of Family A is also wholly consistent with the predictions of the ITPD syndrome hypothesis on infertility. The next step in the procedure of proof is the completion of genetic profiling of families B and C. While this is progressing molecular detailed testing of the haplotypes of the Y-chromosome of these families is being undertaken by Dr. Ken McElreavey in the Pasteur Institute to check for a common founder. When these steps are complete consideration will be given to molecular analysis of dissimilar MZ twins in the families with micro-satellite 
markers to check whether they are SZ, and to molecular examination of any candidate chimeras.

\section{$\overline{\text { Acknowledgments }}$}

The authors would like to thank Professor Geoffrey Machin for attributing zygosity in doubtful cases of like sexed twins and for valuable discussions; Professor Louis Keith for reading the text and valuable suggestions; Dr Ken McElreavey of the Pasteur Institute in Paris for his interest and discussions; and Kenneth Shirlaw for his key contribution in researching pedigrees and valuable suggestions at all stages of the research. Full responsibility, however, for all statements in the article rests with the authors.

\section{Footnotes}

1 For all Figures " $m$ " indicates date of marriage or start of cohabitation.

\section{Footnotes for Diagram A}

1 VI-4 was a still birth.

2 VIII-7 was a still birth.

3 N.B. Diagram includes maternal line twinning in generations VII-IX. See Caption.

\section{Footnotes for Diagram B}

$1 \& 2$ Twin III-5 (sex unknown) and twin were still-births.

\section{Footnotes to Diagram D}

$1 \mathrm{~m}+0$. Died aged 7 months from acute broncio catarrh, bronciopneumonia and cardiac failure.

$2 \mathrm{~m}+3$. Died aged 7 months from marasmus.

$3 \mathrm{~m}+6$. Hiatus hernia.

$4 \mathrm{~m}+10$. Died aged 2 months from debility from birth.

$5 \mathrm{~m}+10$. Duplex kidney.

$6 \mathrm{~m}+16$

$7 \mathrm{~m}+1$.

$8 \mathrm{~m}+3$. DIX-6 has no children after 10 years of marriage.

$9 \mathrm{~m}+3$.

$10 \mathrm{~m}+7$. Duplex kidney, hiatus hernia. Twins DZ on dissimilarity. Twin IX-9 has no abnormalities.

$11 \mathrm{~m}+1$.

$12 \mathrm{~m}+3$.

$13 \mathrm{~m}+1$.

14 No details of date of birth. Duplex kidney, "blue baby", hole in heart, pneumonia.

\section{Footnotes to Diagram E}

1 The brother of EVI-2 had twin girls, who were thought MZ. One girl had boy and girl twins.

$2 \mathrm{~m}+1$.

$3 \mathrm{~m}+3$.

$4 \mathrm{~m}+6$.

5, $6 \& 7 \mathrm{~m}+9$. Triplets died within 2 hours of birth. Case notes and statistical likelihood suggest males MZ.

$8 \mathrm{~m}+11$.

$9 \& 10 \mathrm{~m}+15$. Twin EVII-13 thinks twin sister EVII-12 wanted children. Suspected infertility.
$11 \mathrm{~m}+1$.

$12 \mathrm{~m}+13$. Three children adopted prior to birth of EVIII-3. Suspected infertility in EVII-4.

$13 \mathrm{~m}+4$.

$14 \mathrm{~m}+5$

$15 \mathrm{~m}+7$

$16 \mathrm{~m}+9$

$17 \mathrm{~m}+1$.

$18 \& 19 \mathrm{~m}+3$. EVIII-14 was a stillbirth. EVII-14 was advised by doctor delivering children that twins were $\mathrm{MZ}$ as there was only one placenta. EVIII-13 had no children after 10 years of marriage.

$20 \mathrm{~m}+6$

21 No details available of dates of twin miscarriage or sex, or of dates of birth of siblings.

$22 \mathrm{~m}+4$.

$23 \mathrm{~m}+6$

\section{Footnotes to Diagram $\mathbf{F}$}

1 FV-1 is AV-4.

$2 \mathrm{~m}+1$

$3 \mathrm{~m}+3$. Unmarried.

$4 \mathrm{~m}+6$

$5 \mathrm{~m}+10$.

$6 \mathrm{~m}+10$. Female still birth.

$7 \mathrm{~m}+12$.

$8 \mathrm{~m}+16$. It is possible that FVI-10 was part infertile. He had only one child, although he and his wife came from large families.

$9 \mathrm{~m}+19$. It is possible that FVI-12 was part infertile. There was an 11 years' gap between children. Gynaecological problems of FVI-13 blamed. She had various gynaecological treatments.

10 There is no evidence of twinning in the female line on the mother's side of FVI-13. However her mother's brother had twin daughters, who on phenotype dissimilarity are clearly DZ.

$11 \mathrm{~m}+21$

$12 \mathrm{~m}+4$. It is thought by the children of FVII- 2 that the long gap of 12 years between the second child FVIII-3 and the third child FVIII- 6 was not intentional.

$13 \mathrm{~m}+8$. Unmarried.

$14 \mathrm{~m}+4$. Married late and no children.

$15 \mathrm{~m}+7$

$16 \mathrm{~m}+9$. FVII-9 was born with double hernia and deformed kidneys and weighed $13 \mathrm{lbs}$ at birth. He was medically diagnosed as infertile. He suffered from tuberculosis, although it had almost completely died out generally in Scotland.

$17 \mathrm{~m}+2$.

$18 \mathrm{~m}+5$

$19 \mathrm{~m}+2$. FVII-16 was medically diagnosed as having limited fertility. After a still birth and a miscarriage she underwent fertility treatment.

$20 \mathrm{~m}+1$

$21 \mathrm{~m}+12$. 
$22 \mathrm{~m}+8$. FVI- 14,15 had first child after 8 years of marriage. This is not thought intentional.

$23 \mathrm{~m}+12$.

$24 \mathrm{~m}+1$

$25 \mathrm{~m}+4$.

$26 \mathrm{~m}+8$

$27 \mathrm{~m}+16$.

$28 \mathrm{~m}+1$.

$29 \mathrm{~m}+2$.

$30 \mathrm{~m}+2$

$31 \mathrm{~m}+1$

$32 \mathrm{~m}+2$. Married only briefly and divorced.

$33 \mathrm{~m}+2$. Elected to have no children.

$34 \mathrm{~m}+4$

$35 \mathrm{~m}+7$

$36 \mathrm{~m}+3$

$37 \mathrm{~m}+4$

$38 \mathrm{~m}+6$

$39 \mathrm{~m}+8$.

$40 \mathrm{~m}+9$

$41 \mathrm{~m}+1$

$42 m+2$.

$43 \mathrm{~m}+7$.

$44 \mathrm{~m}+10$.

$45 \mathrm{~m}+2$.

$46 \mathrm{~m}+3$

$47 \mathrm{~m}+5$

$48 \mathrm{~m}+2$. After the birth of FVIII-41,42, FVI-19, 20 elected to have no more children.

$49 \mathrm{~m}+1$.

$50 \mathrm{~m}+2$.

$51 \mathrm{~m}+10$

$52 \mathrm{~m}+3$ and $1 / 2$.

$53 \mathrm{~m}+4$. Miscarriage of twins.

$54 \mathrm{~m}+5$

$55 \mathrm{~m}+1 / 2$

$56 \mathrm{~m}+1$ and $1 / 2$.

$57 \mathrm{~m}+31 / 2$

$58 \mathrm{~m}+7$.

$59 \mathrm{~m}+8$. Pregnancies of FVIII $-51,53,54$ had complications caused by the incompatibility of babies' and mother's blood groups. Mother FVII-25 is AB Negative. Blood changes required by babies.

$60 \mathrm{~m}+16$

$61 \mathrm{~m}+21$. FVIII-1 underwent several courses of infertility treatment and had given up hope of having children, when FIX-1 was born.

$62 \mathrm{~m}+6$

$63 \mathrm{~m}+1$
$64 \mathrm{~m}+4$

$65 \mathrm{~m}+8$.

$66 \mathrm{~m}+2$.

$67 \mathrm{~m}+1$

$68 \mathrm{~m}+1$

$69 \mathrm{~m}+2$

$70 \mathrm{~m}+3$.

$71 \mathrm{~m}+0$

$72 \mathrm{~m}+1$.

$73 \mathrm{~m}=4$.

$74 \mathrm{~m}+5$.

$75 \mathrm{~m}+8$.

$76 \mathrm{~m}+15$.

$77 \mathrm{~m}+6$

$78 \mathrm{~m}+7$.

$79 \mathrm{~m}+8$.

$80 \mathrm{~m}+9$

$81 \mathrm{~m}+6$.

$82 \mathrm{~m}+8$.

$83 \mathrm{~m}+7$

$84 \mathrm{~m}+9$

$85 \mathrm{~m}+2$.

$86 \mathrm{~m}+5$.

$87 \mathrm{~m}+2$.

$88 \mathrm{~m}+0$.

$89 \mathrm{~m}+0$

\section{Footnotes to Diagram G}

1 The dates of births of the children of AV-5,6 are not known exactly, although this could be established. The 10 children were spaced over an 18-year period.

2 GVI-3 was unmarried and suffered from rheumatoid arthritis and was in a wheelchair from early childhood until death aged 61

3 GVI-4,5 have always been considered identical. Both twins have suffered from heart trouble aneurisms. In hospital GVI-6 was diagnosed as having no function in one kidney, but it is not known whether GVI-5 also has this deficiency. GVI-5 claims that his small family was a question of choice. GVII-5 was born within 20 months of the marriage. They then elected to wait to have any more but when they thought of having more, they had left it too late. This story may be true, but equally likely is that there was trouble having more children. It is unlikely that members of this family would admit to infertility. GVI-6 claims that GVII-5, who has been married for 20 years without children, is likely to have elected to have no children.

4 GVI-10 was unmarried and suffered all his life from severe epilepsy.

5 Unmarried.

6 Died aged 44 from heart trouble - aneurism.

\section{Footnotes to Diagram $\mathbf{H}$}

1 Twins HVII-1,2 classed DZ on descriptions of pronounced phenotype dissimilarity. A son of HVII-2 had duplex kidney. 
2 Hiatus hernia.

$3 \mathrm{~m}+0$. Died aged 7 months from acute broncio catarrh, bronchiopneumonia and cardiac failure.

$4 \mathrm{~m}+3$. Died aged 7 months from marasmus.

$5 \mathrm{~m}+6$. Hiatus hernia.

$6 \mathrm{~m}+10$. Died 2 months from debility from birth.

$7 \mathrm{~m}+10$. Duplex kidney.

$8 \mathrm{~m}+16$.

$9 \mathrm{~m}+1$.

$10 \mathrm{~m}+3$. No children after 10 years of marriage but no infertility admitted by HIX-6.

$11 \mathrm{~m}+3$.

$12 \mathrm{~m}+7$. Duplex kidney. Hiatus hernia. Twin HIX-10 does not have conditions. Twins classed DZ on phenotype dissimilarity.

$13 \mathrm{~m}+1$.

$14 \mathrm{~m}+3$.

$15 \mathrm{~m}+1$.

16 No details of date of birth. Duplex kidney, "blue baby", pneumonia and "hole in the heart".

\section{$\overline{\text { References }}$}

Bulmer, M. G. (1970). The biology of twinning in man. Oxford: Clarendon Press.

Carmelli, D., Hasstedt, S., \& Anderson, S. (1981). Demography and genetics of human twinning in the Utah Mormon Genealogy. Progress in Clinical and Biological Research, 69A, 81-93.

Davenport, C. B. (1920). Influence of the male in the production of human twins. American Nature, 54, 122.

Golubovsky, M. D., \& Golubovskaya, I. N. (1984). Possible cytogenetic mechanisms of direct paternal influence on twinning tendency in humans and their consequencies. Genetika (Russian), 20, 1043-1050.

Golubovsky, M. D. (1984). A pedigree in which multiple births are associated with infertility. Genetika (Russian), 20(6), $1052-1054$.

Golubovsky, M. D. (1998). Paternal gametic genes and infertilitytwinning paternally dependent familial syndrome. Twin Research, 1, 90.

Golubovsky, M. D. (2002). Paternal familial twinning: Hypothesis and genetic/medical implications. Twin Research, 2, 75-86.

Harvey, M. A., Huntley, R. M., \& Smith, D. W. (1977). Familial monozygotic twinning. Journal of Pediatrics, 90, 246-248.
Kanaev, I. I. (1959). Twins (In Russian; p 382). Izd Akad Nauk: Moscow-Leningrad.

Khoury, M. J., \& Erickson, J. D. (1983). Maternal factors in dizygotic twinning: evidence from interracial crosses. Annals of Human Biology, 10(5), 409-415.

Lichtenstein, P., Kallen, B., \& Kostler, M. (1998). No paternal effect on monozygotic twinning in the Swedish twin registry. Twin Research, 4, 212-215.

Lil'in, E. T., \& Gindilis, V. M. (1976). Genetic-statistical analysis of multiple births in humans. Genetic analysis of predisposition to multiple birth. Genetika, 12(9), 118-127.

Lush, R. H. (1925). Inheritance of twinning. Journal of Heredity, 16, 273-278.

Machin, G.A. (1996). Some causes of genotypic discordance in monozygotic twin pairs. American Journal of Medical Genetics, 61, 216-228.

Machin, G. A., \& Bamforth, F. (1996). Zygosity and placental anatomy in 15 consecutive sets of spontaneously conceived triplets. American Journal of Medical Genetics, 61, 247-252.

McElreavey, K., Vilain, N., Abbas, N., Herkskowitz, I., Fellous, M. (1993). A regulatory cascade hypothesis for mammalian sex determination: SRY represses a negative regulator of male development. Proceedings of the National Academy of Sciences of the United States of America, 90, 3368-3372.

McElreavey, K., \& Fellous, M. (1999). Sex determination and the Y-chromosome. American Journal of Medical Genetics, 89, 176-185.

Michels, V. V., \& Riccardi, V. M. (1978). Twin recurrence and amniocentesis: Male and MZ heritability factors. Birth Defects - Original Article Series, 14(6), 201-211.

Parisi, P., Gatti, M., Prinzi, G., \& Caperna, G. (1983). Familial incidence of twinning. Nature, 304, 626-628.

Peiper, A. (1923). Zur Vererbung der Zwillingsswangerschaft durch den Mann. Klinische Wochenschrift, ii, 1651.

Rietvald, M. J., Valk, J. C., Bongers, I. L., Stroet, T. M., Slagboom, P. E., \& Boomsma, D. I. (2000). Zygosity diagnosis in young twins by parental report. Twin Research, 3, 134-141.

St Clair, D., St Clair, J., Swainson, C., Bamforth, F., \& Machin, G. (1998). Twin zygosity testing for medical purposes. American Journal of Medical Genetics, 77, 412-414.

Southwick, W. E. (1939). Sex ratios and twin producing kindreds. American Nature, 73, 44-68.

Wasserman, P. M., Jovine, L., \& Litscher, E. (2001). A profile of fertilization in mammals. Nature Cell Biology, 3, 59-64. 